\title{
Combined Percutaneous Endoscopic and Fluoroscopic Approach for Placement of Gastrostomy and Conversion to Gastrojejunostomy-A Novel Technique
}

\author{
Shuo Li ${ }^{1}$ Shelby Breit ${ }^{2 *}$ Nishant Gupta ${ }^{3} \quad$ Christopher Baalman $^{1} \quad$ Timothy Gronlie $^{1}$ James Homan ${ }^{1}$ \\ Kermit Rust ${ }^{1}$
}

${ }^{1}$ Department of Radiology, University of Kansas School of MedicineWichita, Wichita, Kansas, United States

2 School of Medicine, University of Kansas School of Medicine, Wichita, Kansas, United States

${ }^{3}$ Department of Radiology, Columbia University at Bassett

Healthcare, United States

J Clin Interv Radiol ISVIR 2022;6:154-156.
Address for correspondence Shelby Breit, University of Kansas School of Medicine, 1010 N. Kansas, Wichita Ks. 67214, United States (e-mail: Sbreit@kumc.edu).

\section{Keywords \\ - Endoscopy \\ - gastrojejunostomy}

\section{Introduction}

Interventional radiologists (IR) perform a variety of procedures using CT, MRI, ultrasonography, and fluoroscopy. However, IR should not be limited to these modalities only. There is a growing trend of combining endoscopic and radiologic imaging guidance by IR to perform similar endoscopic minimally invasive procedures. ${ }^{1}$

Gastrojejunostomy (GJ) enables patients to meet their caloric requirements enterally, when there is concurrent need for gastric venting or gastric reflux. There are many indications for GJ placement. GJ and gastrostomy can be placed by IR using percutaneous radiological technique. $^{2}$ This is advantageous when the patient cannot tolerate oral cannulation of the stomach and small bowel.

This article describes a novel technique, combining the use of endoscopy and fluoroscopy for placement of and conversion to GJ catheter in difficult cases, namely, percutaneous endoscopic and radiologic (PER) GJ.

published online September 17, 2021
DOI https://doi.org/ 10.1055/s-0041-1736078. ISSN 2457-0214.
This technique was created because of the difficulty of cannulating the pylorus from unfavorable angle of the gastrostomy tube tract in a significant number of patients by endoscopic guidance. ${ }^{3}$ The PER technique has been successfully performed by the authors in both pediatric and adult patients. The authors hope to introduce a method that can significantly reduce fluoroscopy time and radiation dose.

\section{Description of Technique}

\section{Endoscopes}

The endoscope used in our case is a $10 \mathrm{Fr} 214-\mathrm{cm}$ SpyGlass DS cholangioscope (Boston Scientific, Malborough MA, USA). Other endoscopes are also available.

\section{Technique}

For new GJ, the technique is outlined as below:

1. The procedures were performed under conscious sedation. The stomach was inflated with a nasogastric tube. The liver edge was marked with ultrasound.

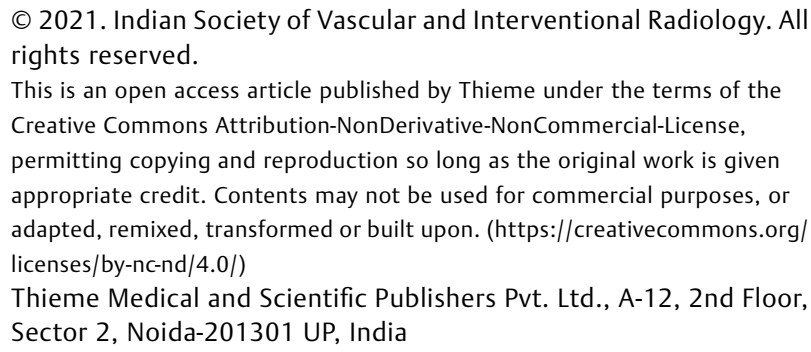

This is an open access article published by Thieme under the terms of the Creative Commons Attribution-NonDerivative-NonCommercial-License, permitting copying and reproduction so long as the original work is given appropriate credit. Contents may not be used for commercial purposes, or adapted, remixed, transformed or built upon. (https://creativecommons.org/ licenses/by-nc-nd/4.0/)

Thieme Medical and Scientific Publishers Pvt. Ltd., A-12, 2nd Floor, Sector 2, Noida-201301 UP, India 
2. Three T-tacks were placed.

3. An introducer needle was advanced into the stomach, followed by access of the stomach with a 0.035 -inch stiff wire.

4. The track was dilated to accept a $14 \mathrm{Fr}$ valved sheath; the sheath length depends on body habitus. A longer sheath can be trimmed. Securing the sheath to the skin with sutures is helpful. The side arm of the sheath can be used to maintain inflation of the stomach. The sheath can also be torqued to assist in directing the endoscope.

5. Through the sheath, the endoscope is inserted into the stomach.

6. Using intermittent fluoroscopy, the endoscope is oriented to face the pylorus. The pyloric sphincter can be cannulated, using the endoscope alone or using a wire through the working port of the endoscope.

7. Advance the endoscope into the jejunum, either freely or over a wire. If there is concern for perforation, in case of gastric or duodenal ulcer, a wire can be advanced through the working port of the endoscope until the tip is just visible.

8. Advance a stiff exchange length wire through the working port of the endoscope. For SpyGlass DS, this will require the $450 \mathrm{~cm}$ length Dreamwire (Boston Scientific, Malborough MA, USA).

9. The endoscope is removed with the sheath while maintaining wire access.

10. The track is serially dilated using fascial dilators for a peel away sheath, appropriately sized for the chosen GJ.

11. The GJ tube, such as the Avanos Mic GJ tube, is advanced over the wire into the duodenum and secured with the retention balloon.

For conversion or replacement of GJ, the technique is outlined below:

1. The stomach is cannulated with the placement of a $14 \mathrm{Fr}$ valved sheath.

2. Secure the sheath to the skin. A purse-string suture around the sheath may help maintain an inflated stomach. The sheath can also be torqued to assist in directing the endoscope.

3. Inflate the stomach with air or saline; this is optional but improves visualization of pyloric sphincter.

4. Insert the endoscope into the stomach.

5. Advance the endoscope into the duodenum and subsequently the jejunum in a similar fashion, as detailed above. Once accomplished, the endoscope and sheath is removed over an exchange length wire.

6. The GJ tube is now advanced over the wire and into the jejunum. Catheter tip and gastric port positions are confirmed by injection of contrast ( $\mathbf{- F i g . 1} \mathbf{1}$ ).

7. Secure the catheter with the retention balloon.

\section{Troubleshooting}

Intermittent fluoroscopic images can assist in reorientation of the endoscope as well as the relative position of the endoscope within the small bowel.
A wire can be advanced through the working port, so that the tip is just beyond the tip of the endoscope to "prop" up a collapsed gastric wall.

Guidewire prolapse into the stomach is a known difficulty. Prolapsed loop can be reduced by anchoring the wire with an inflated Fogerty balloon in the small bowel.

\section{Discussion}

Combining endoscopic techniques with radiologic techniques expands the armamentarium of tools with new solutions to old problems.

Current literature exists in combining endoscopic techniques with imaging guidance in biliary, gastrointestinal, and urologic applications. ${ }^{1}$ Endoscopy can be particularly helpful when image-guided intervention fails, such as difficult crossing of tight stenosis and/or stricture. Kim et al found that gastrostomy to GJ conversion can fail in up to $12.1 \%$ of cases, with higher rates of failure in nonradiologically placed gastrostomies. $^{4}$

Radiation dose involved in conversion procedures can be as high as 430.6 mGy. ${ }^{3}$ In contrast, the case in - Fig. $\mathbf{1}$ had a total air kerma of 18.9 mGy. Wan et al found the mean cumulative air kerma was $41.13 \mathrm{mGy}$ in 175 pediatric GJ tube exchanges. ${ }^{5}$ The pediatric case in - Fig. 2 of a conversion has a dose of only $0.584 \mathrm{mGy}$. Although anecdotal, the authors here believe that the combined technique can significantly reduce patient and operator exposure

\section{Future directions}

Although there are encouraging signs when using the PER technique, more rigorous studies to compare technical

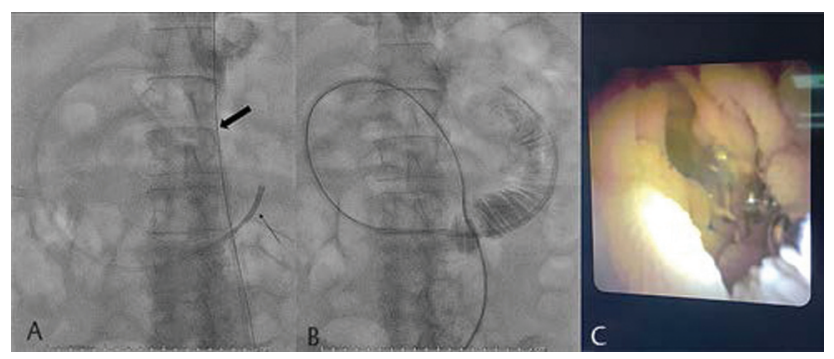

Fig. 1 Placement of adult gastrostomy to gastrojejunostomy (G]) tube in a patient with history of previous cerebrovascular accident (CVA), recurrent aspiration and GJ tube dependent for nutritional support. The patient's previous feeding tube was dislodged at the nursing facility. (a) A tandem SpyGlass endoscope (thin arrow) and a hydrophilic safety wire (thick arrow) were inserted into the stomach in panel A. The endoscope has been guided into the fourth portion of the duodenum under direct visualization. (b) The endoscope was exchanged for a new $G$ J tube using standard wire exchange technique. Contrast injected through jejunal port shows appropriate positioning of the new feeding tube. (c) Photo of visual display of the endoscope. In this case, the output was connected directly to the fluoroscopy monitor, allowing concurrent visualization of the last image hold as well as the endoscopic view. This exchange required 3.5 minutes of fluoroscopy time with 18.9 mGy of total air kerma. In contrast, the previous exchange (not shown) required 13.2 minutes of fluoroscopy time with a $232 \mathrm{mGy}$ of total air kerma. 


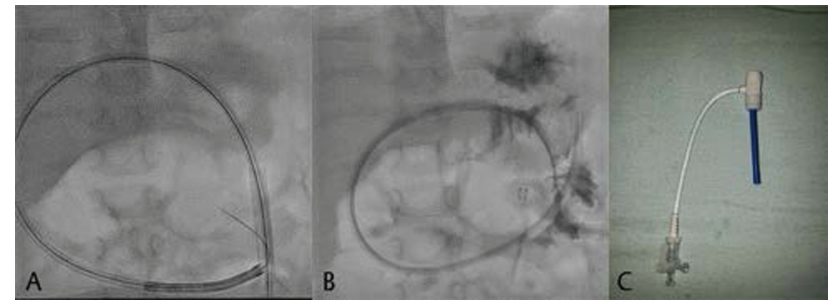

Fig. 2 Example of the percutaneous endoscopic and radiologic (PER) technique in a pediatric patient. This case was done in a toddler with congenital nephrotic syndrome. Despite gastrostomy placement, there was persistent vomiting and failure to thrive, and the decision was made to convert to a gastrojejunostomy (GJ) tube. (a) An endoscope has been guided through a trimmed 14 French valved sheath seen in (c). The safety wire in the stomach has already been removed. An exchange length wire is seen through the working port of the endoscope, with the floppy atraumatic tip just outside the tip of the endoscope. (b) Contrast injected through the jejunal port confirms appropriate positioning. This de novo conversion required 0.3 minutes of fluoroscopy time and 0.584 mGy of total air kerma.

success rates, fluoroscopy time, and radiation exposure are needed.

Disposable endoscopes can considerably increase the cost of procedure. Shorter, reusable endoscopes specifically designed for use by the IR may be needed.
Comfort with this procedure will also allow for other possible types of gastrointestinal intervention, such as gastric outlet stenting, esophageal stenting, rendezvous for biliary intervention, and more.

\section{Conflict of Interest}

None declared.

\section{References}

1 Srinivasa RN, Pampati R, Patel N, et al. Interventional radiologyoperated endoscopy: indications, implementation, and innovation. Semin Intervent Radiol 2018;35(05):477-485

2 Lyon SM, Pascoe DM. Percutaneous gastrostomy and gastrojejunostomy. Semin Intervent Radiol 2004;21(03):181-189

3 Lee A, Park J, Cho S, Bonilla-Yoon I, Lee E. Double dragons (Kumpe) technique for gastrostomy to gastrojejunostomy conversion: a novel approach. J Vasc Interv Radiol 2013;24(04): S139-S40

4 Kim CY, Patel MB, Miller MJ Jr, Suhocki PV, Balius A, Smith TP. Gastrostomy-to-gastrojejunostomy tube conversion: impact of the method of original gastrostomy tube placement. J Vasc Interv Radiol 2010;21(07):1031-1037

5 Wan JJ, Hudnall M, Kohlbrenner R, et al. Mind the Zap: radiation exposure for pediatric gastrojejunostomy tube exchanges. Dig Dis Interv 2017;1(S 04)S1-S20 